\title{
A CONCEPTUAL FRAMEWORK TO ENERGY ESTIMATION IN BUILDINGS USING AGENT BASED MODELING
}

\author{
Elie Azar \\ Carol Menassa \\ Department of Civil and Environmental Engineering \\ University of Wisconsin-Madison \\ 2205 Engineering Hall, 1415 Engineering Drive \\ Madison, WI 53706, USA
}

\begin{abstract}
Actual energy consumption in buildings is typically different from predictions during the design phase. While differences in occupant energy usage characteristics play an important role in this variation, actual energy estimation software do not account for this factor. This paper proposes a new approach for energy estimation in buildings using a combination of traditional energy calculation software along with agentbased simulation modeling. First, the difference in energy consumption levels for different types of occupancy energy usage characteristics is identified by building energy models adapted for each type of behavior. Then, an agent-based simulation model simulates the influence that people with different behaviors have on each other, resulting in potential changes in energy usage characteristics over time. By combining these two methods, more customized energy studies can be performed resulting in more accurate energy consumption estimates.
\end{abstract}

\section{INTRODUCTION}

The building sector accounts for 30 to 40 percent of global energy use (UNEP-SBCI 2007) and 40 percent of the world's carbon dioxide emissions (Yudelson 2010). When looking at the energy consumption of buildings from a life-cycle point of view, more than 80 percent of consumed energy occur when the building is in actual use (UNEP-SBCI 2007). Therefore, an understanding of the energy use during the operation phase of a given building becomes quite essential for more accurate energy estimation during the design phase. Obtaining accurate energy estimates is key to energy efficiency, leading to economical and environmental benefits.

Energy modeling is widely used in the U.S. and the world to estimate actual and future energy performance. However, several limiting factors such as the complexity of buildings, weather, and variations in building schedule and occupancy are causing the energy estimates obtained from different modeling techniques to differ significantly from actual energy use (Turner and Frankel 2008). As a matter of fact, the variation between predicted and actual energy consumption in buildings is estimated to be greater than 30 percent (Yudelson 2010; Dell'lsola and Kirk 2003; Soebarto and Williamson 2001). This variation can even reach a value of 100 percent in particular cases such as laboratory buildings with high process loads (Turner and Frankel 2008).

The deviation from energy design predictions can be attributed to misunderstanding and underestimating the important role that the occupant's energy characteristics play in determining energy consumption levels (Hoes et al. 2009); the term 'occupant's energy characteristics' being defined as the presence of people in the premises and the actions they perform (or do not perform) to influence the level of energy consumption (Hoes et al. 2009). While this important factor does change with time (Jackson 2005), it is 


\section{Azar and Menassa}

currently modeled as a static parameter in the existing energy estimation models. So in order to obtain more accurate energy estimates, occupants' energy consumption characteristics and their variation over time need to be better understood and accounted for in building performance simulations (Hoes et al. 2009).

The aim of this paper is to study the impact of modeling the change in occupant's energy usage characteristics on total building energy consumption levels. An experimental energy simulation model was built for the purpose of this study consisting of a $1000 \mathrm{sq} \mathrm{ft}$ graduate student office of a university building, accommodating 10 full-time graduate students over a period of 60 months (5 years). The results from this model show that when accounting for changes in occupants energy usage characteristics, the total levels of energy consumption could vary by more than $20 \%$ from traditional energy estimates that ignore the occupancy effect.

\section{BACKGROUND AND RELATED WORK}

Energy simulation software including eQuest, Energy-10, TRNSys, and Energy Plus, which are commonly used in the industry, are very sensitive to occupancy related inputs such as energy consumption rates and building schedules (Turner and Frankel 2008). The Clevenger and Haymaker (2006) study on the impact of building occupancy on energy simulation models showed that estimated energy consumption can change by more than $150 \%$ when occupants with different energy consumption rates were considered. Furthermore, a change in only one factor such as the level of isolation of a building might result in a $40 \%$ change in the total estimated consumption. This rate is not only function of the design, but also a function of the frequency of opening of doors and windows by the occupants.

Even though a change in the occupants' consumption characteristics might have a significant influence on total energy consumption levels, actual energy simulation software do not account for this occupancy related factor (Hoes et al. 2009). This is where agent-based modeling can be used to simulate changes in occupants' energy usage characteristics, and assist traditional energy simulation software. As defined by Axtell (2000), an agent-based model consists of "individual agents, commonly implemented in software as objects. Agent objects have states and rules of behavior. Running such a model simply amounts to instantiating an agent population, letting the agents interact, and monitoring what happens". So by using agent-based modeling, almost all behavioral aspects of agents can be modeled (XJ Technologies 2009).

Agent-based modeling has already been used to assist energy simulation software for buildings. More specifically, Erickson et. al (2009) used agent-based modeling to model the rooms' occupancy in buildings in order to optimize the HVAC loading, and hence avoid typical over sizing problems. This research showed that by simulating occupancy usage patterns, HVAC energy usage can be reduced by around $14 \%$.

Another example where agent-based modeling was used to assist HVAC design was presented by Li et al. (2009). In this study, the occupancy of an emergency department of a health care facility was first modeled. The obtained numbers were then used to optimize the sizing of the HVAC system, avoiding unnecessary or excessive air conditioning loads. This organizational simulation model showed that the required capacity of the ventilation system might change by as much as $43 \%$ when a building's occupancy is properly modeled.

Literature specific to assisting energy simulation models with agent-based modeling tends to mainly focus on HVAC calculation. While HVAC accounts for $31 \%$ of the total energy consumption for an average U.S. commercial building, other energy consumption sources such as lighting, computers, and hot water supply account for more than 33\% (InterAcademy Council 2007). As a consequence, there is a need to broaden the scope of study to include energy consumption sources other than HVAC, while accounting for the occupancy effect on the levels of energy consumption. 


\section{Azar and Menassa}

\section{OBJECTIVES}

The objectives of this study are to model occupants with different energy usage characteristics, and then model the changes in these usage characteristics over time to study the variation in the energy consumption estimate. This modified estimate is to be compared to another estimate obtained using a traditional estimation method, where the dynamic aspect of occupancy is not considered. The proposed model is applied to a $1000 \mathrm{sq} \mathrm{ft} \mathrm{graduate} \mathrm{student} \mathrm{office} \mathrm{previously} \mathrm{described} \mathrm{in} \mathrm{the} \mathrm{introduction} \mathrm{section.}$

First, modeling the energy usage characteristics of occupants is essential because of the impact that occupant's behavior can have on the total energy use levels. The energy consumption levels of a room, whose occupants overuse energy, may differ by more than $150 \%$ from when the same room is occupied by energy efficient users (Clevenger and Haymaker 2006).

Second, after identifying the energy usage characteristics of the occupants, it is important to model the changes in these occupants' characteristics over time. For example, an occupant might change his energy usage characteristics by adopting more energy efficient practices or on the contrary, adopt bad consumption habits. Many factors could lead to such changes in energy consumption behavior such as 'green' social marketing campaigns or financial incentives that encourage energy efficiency (Jackson 2005). The only factor considered in this study is the 'word of mouth' effect, which is considered to be a very influential channel of communication (Allsop et al. 2007). The 'word of mouth' effect is a marketing concept defined as a type of informal, person-to-person communication between a perceived noncommercial communicator and a receiver regarding a brand, a product, an organization or a service (Harrison-Walker, 2001). In this study, the 'word of mouth' effect represents the influence that each occupant exerts on the other occupants in the same room to change their energy consumption habits.

Finally, the modeled energy characteristics of the occupants will be used to obtain energy consumption estimates that correspond to the change in occupancy energy usage characteristics.

\section{METHODOLOGY}

To represent the differences in the occupant's energy usage characteristics, three categories of occupants were first considered. The first category is the group of 'High Energy Consumers', representing occupants that over consume energy and water. Second, occupants that make minimal efforts towards energy and water savings form the 'Medium Energy Consumers' category. The last category, the 'Low Energy Consumers', represents the occupants that use energy and water very efficiently.

In order to estimate energy consumption as a function of occupancy, the proposed methodology combines a traditional building energy estimating model with an agent-based model. For the purposes of this research, 'eQuest' is used as the traditional energy modeling framework and 'Anylogic' is used to build the agent based model. First, using eQuest, energy and water consumption rates per person are determined for each category of occupants: High, medium, and low energy consumers. Then, the agent-based model simulates the change in energy characteristics due to the 'word of mouth effect'. The results from the two models are finally combined, resulting in energy consumption estimates that account for the different occupants' energy characteristics and their change over time.

\section{1 'eQuest' Energy Simulation Model}

Many energy simulation software are commonly used in the industry such as Energy-10, TRNSys, Energy Plus and others. eQuest, a software available through the department of energy's website, was chosen for this study because of its comprehensive yet very easy-to-use features and interface. eQuest's simulation engine is derived from the latest version of DOE-2, one of the most widely recognized and respected building energy analysis program in use today (eQuest 2009).

As mentioned earlier, the experimental model consists of a $1000 \mathrm{sq} \mathrm{ft}$ graduate student room accommodating 10 students over a period of 60 months. This room is located at the ground floor of a multistory university building, located in the city of Madison-Wisconsin. As shown in Figure 1, the room has four windows facing the East and one door facing the North. These are the only two faces that are exposed to 
the exterior. The Southern/ Western faces and the roof have no openings. They are considered to be in contact with air conditioned areas, representing other sections of the building. The room also has internal window blinds (not shown in Figure 1) that can be manually adjusted, opened or closed, by the occupants.

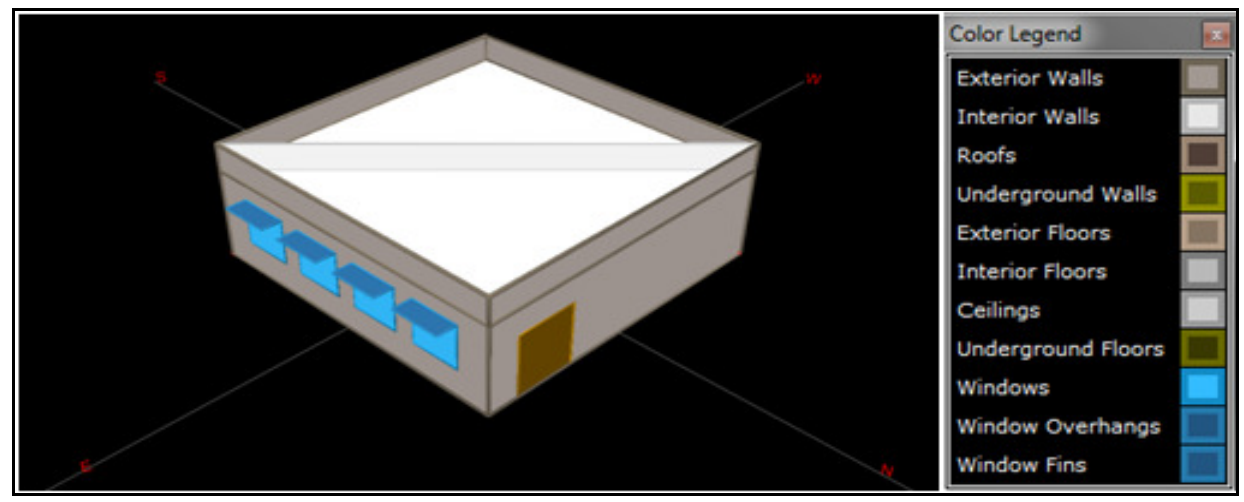

Figure 1: Graduate Student Room in eQuest

To determine the energy use during the operational phase of the building, the following energy categories need to be studied: heating, cooling, ventilation, lighting, domestic hot water, and other miscellaneous equipment loads (Dell'lsola and Kirk 2003). For this purpose, six energy consumption sources summarized in Table 1 were studied in the proposed model: (1) HVAC heating, (2) HVAC cooling, (3) area lighting, (4) task lighting, (5) equipment (computers), and (6) hot water supply. For each one, three main assumptions were made to build the eQuest model: (1) the type of energy needed to run each source whether electricity or gas, (2) the estimated energy consumption rates, and (3) the level of control the occupants have on these energy use rates.

Starting with the first two categories, HVAC heating and HVAC cooling are respectively powered by Natural Gas and Electricity, as used in typical commercial buildings. For this model, it was assumed that the occupants do not have direct control over these sources since a central air conditioning system maintains the room temperature between $70^{\circ} \mathrm{F}$ and $76^{\circ} \mathrm{F}$ when occupied and between $64^{\circ} \mathrm{F}$ and $82^{\circ} \mathrm{F}$ when unoccupied. These temperatures were recommended by eQuest for typical commercial university buildings. The occupants however indirectly affect the room temperature by controlling the lighting and equipment use, in addition to the positions of the internal window blinds. In the case of area and task lighting, the occupants have total control over these two energy consumption sources by using manual switches. These sources are powered by electricity and consume on average $1.2 \mathrm{~W} / \mathrm{SqFt}$ and $0.5 \mathrm{~W} / \mathrm{Sqft}$ respectively (California Energy Commission 2007). Also controlled by occupants are desktop computers with monitors. On average, office computers consume $250 \mathrm{~W} / \mathrm{PC}$ (Bray 2006). The last category is hot water consumption, which is also controlled by occupants. As recommended by eQuest, the average consumption rate in commercial buildings is $1.2 \mathrm{gal} / \mathrm{day} / \mathrm{person}$. All of the six energy consumption categories in addition to the assumptions made are summarized in Table 1.

Table 1: Energy Consumption Sources

\begin{tabular}{|l|l|l|l|}
\hline \multicolumn{1}{|c|}{$\begin{array}{c}\text { Energy Consumption } \\
\text { Categories }\end{array}$} & Energy Source & \multicolumn{1}{|c|}{ Estimated Rate } & Controlled by Occupants \\
\hline HVAC - Heating & Natural Gas & Determined by eQuest & No (fixed thermostat) \\
\hline HVAC - Cooling & Electricity & Determined by eQuest & No (fixed thermostat) \\
\hline Lighting - Area & Electricity & $1.2 \mathrm{~W} / \mathrm{SqFt}$ & Yes \\
\hline Lighting - Task & Electricity & $0.5 \mathrm{~W} / \mathrm{SqFt}$ & Yes \\
\hline Computers & Electricity & $250 \mathrm{~W} / \mathrm{PC}$ & Yes \\
\hline Hot Water (Bathrooms) & Natural Gas & $1.2 \mathrm{gal} / \mathrm{day} /$ person & Yes \\
\hline
\end{tabular}




\section{Azar and Menassa}

To better understand the impact that occupants have on the total energy consumption levels, a breakdown of the room's energy consumption sources was obtained from eQuest as shown in Figure 2. For the electric consumption, the categories that the occupants directly control, which are area/task lighting and miscellaneous equipment (computers), represent $79 \%$ of the total electric consumption. Hence, a change in occupants energy usage characteristics affects $79 \%$ of the total electric consumption levels. On the other hand, the occupants have the control over only $13 \%$ of the gas consumption since they only control the level of hot water consumption in this model, while the HVAC heating being controlled by fixed thermostat temperatures. So when comparing occupants with different consumption characteristics, the difference in the electric consumption rates is expected to be higher than the difference in gas consumption for this particular example.

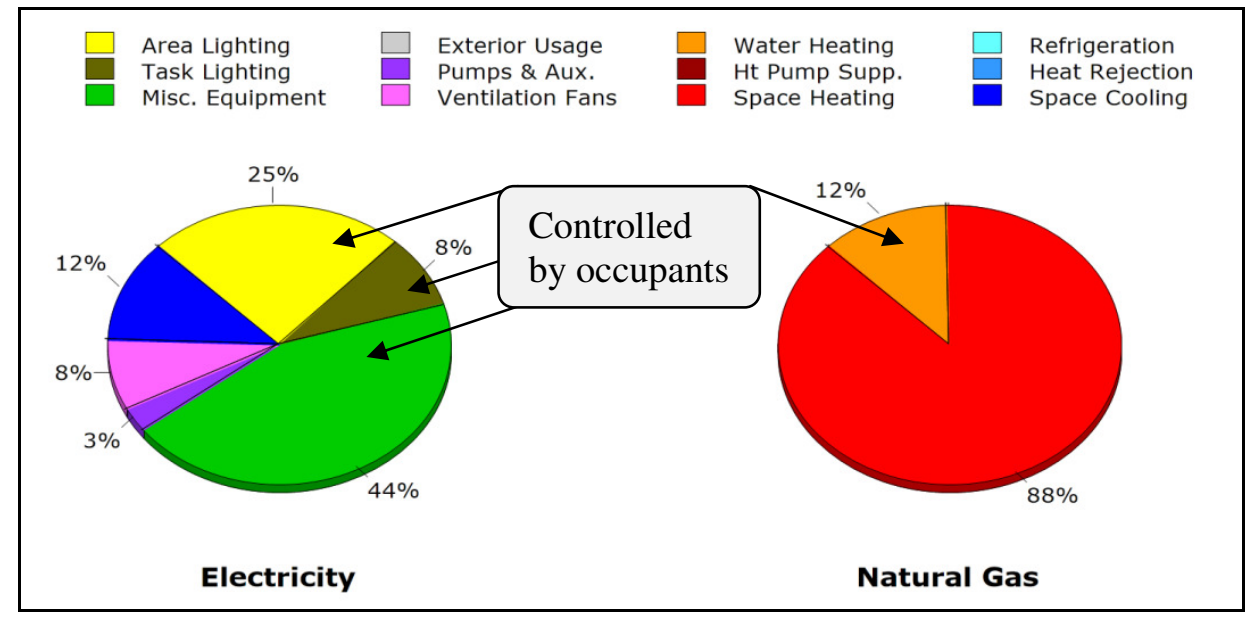

Figure 2: eQuest Energy Breakdown Screenshot

As previously stated, the purpose of this section is to determine the total energy consumption per person for each of three categories of occupants: High, medium, and low energy consumers. Thus, three eQuest models were built using occupancy related inputs that reflect the energy consumption characteristics of the three categories. By changing the eQuest inputs that are related to occupancy, the three categories of occupant behavior are modeled and the corresponding energy use rates are obtained. More specifically, the three inputs that were used in the eQuest model are: (1) blinds positions, (2) lighting/equipment schedules, and (3) hot water use.

First, blinds positions were considered since important energy savings can be achieved by using blinds to block the sun during the hot season and by keeping them open in the cold season, using the sun as a lighting and also heating source. As shown in Table 2, high energy consumers are assumed to close the blinds for $20 \%$ of the time during all seasons, without adjusting the blinds to weather conditions. This value was recommended by eQuest. On the other hand, medium energy consumers make some energy saving efforts during the summer by closing the blinds during $40 \%$ of the time, hence reducing the solar heat and consequently the air conditioning cooling loads. Finally, low energy consumers optimize the use of blinds by closing them more often during the summer, while opening them during winter days and closing them at night to trap the heat inside the office.

The second input is the lighting/equipment schedules where the eQuest occupancy schedules were adjusted to account for the overuse of equipment by the 'High Energy Consumers' and the energy savings made by the 'Low Energy Consumers'. As shown in Table 2, High energy consumers leave the equipment (computers) and lights on not only during the building opening hours, but also during additional hours. Medium energy consumers only use equipment and lights during working hours whereas low energy consumers minimize their energy consumption by taking advantage of day lighting and by turning the equipment and switching the lights off whenever they are out of the office. 
The last input is water consumption where eQuest suggested a value of 1.20 Gallon/Pers/Day for a typical university building. This value was used for the medium energy consumer while the high and the low energy consumers were assumed to consume 20 percent more, and 20 percent less respectively.

Table 2: Energy Consumption Characteristics

\begin{tabular}{|c|c|c|c|}
\hline & High Consumers & Medium Consumers & Low Consumers \\
\hline Blinds Positions & $\begin{array}{l}\text { All seasons: } \\
\begin{array}{l}20 \% \text { of the time } \\
\text { closed. }\end{array}\end{array}$ & $\begin{array}{l}\text { Spring/Fall/Winter: } \\
20 \% \text { of the time } \\
\text { closed. } \\
\text { Summer: } \\
\begin{array}{l}40 \% \text { of the time } \\
\text { closed. }\end{array}\end{array}$ & $\begin{array}{l}\text { Spring/Fall: } \\
20 \% \text { of the time } \\
\text { closed. } \\
\text { Summer: } \\
60 \% \text { of the time closed } \\
\text { during operation and } \\
90 \% \text { after hours. } \\
\text { Winter: } \\
10 \% \text { of the time closed } \\
\text { during operation and } \\
90 \% \text { after hours. }\end{array}$ \\
\hline $\begin{array}{l}\text { Lighting/Equipment } \\
\text { Running Schedules }\end{array}$ & $\begin{array}{l}\text { Building } \\
\text { hours }+ \text { opening } \\
\text { hours }\end{array}$ & $\begin{array}{l}\text { Building opening } \\
\text { hours }\end{array}$ & $\begin{array}{l}\text { Half of the building } \\
\text { opening hours time }\end{array}$ \\
\hline Hot Water Consumption & $\begin{array}{l}\text { 1.44 Gallon/Pers/Day } \\
\text { ( } 20 \% \text { more than the } \\
\text { 'Medium Consumers') }\end{array}$ & $\begin{array}{l}1.20 \text { Gallon/Pers/Day } \\
\text { (as recommended by } \\
\text { eQuest) }\end{array}$ & $\begin{array}{l}0.96 \text { Gallon/Pers/Day } \\
(20 \% \text { less than the } \\
\text { 'Medium Consumers') }\end{array}$ \\
\hline
\end{tabular}

By using the three different sets of inputs shown in Table 2, monthly per person energy consumption rates were obtained for each of the three categories. Figures 3 and 4 show the difference in the total Electric and Gas consumptions per person over a period of one year for high, medium, and low consumers.

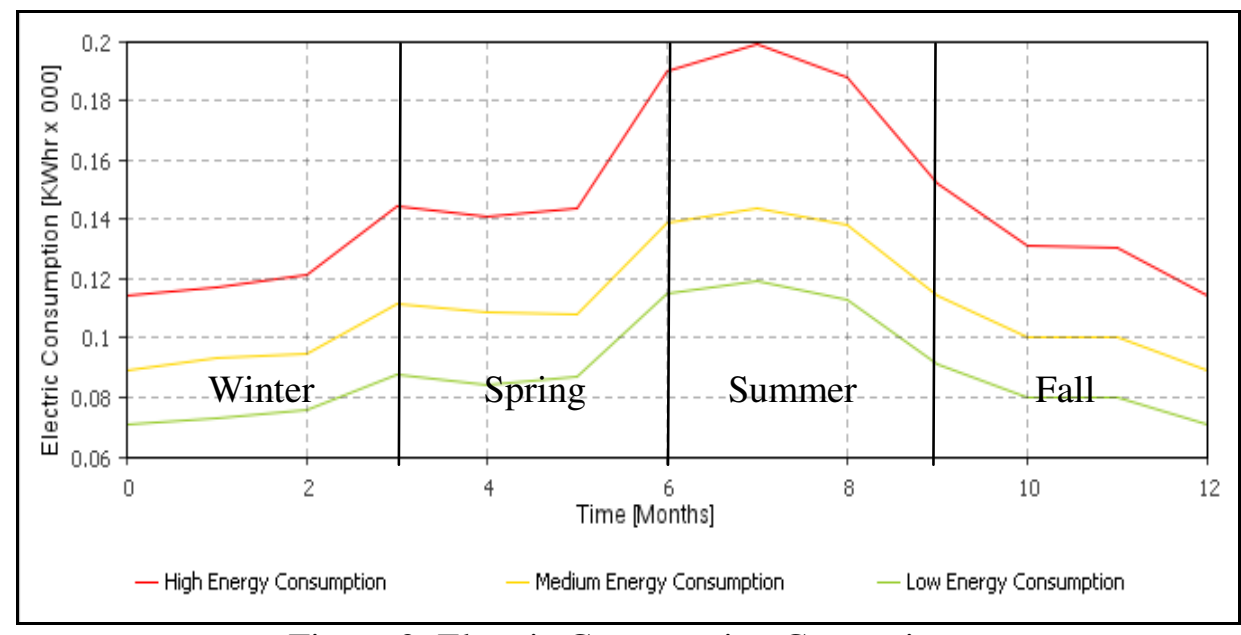

Figure 3: Electric Consumption Comparison 


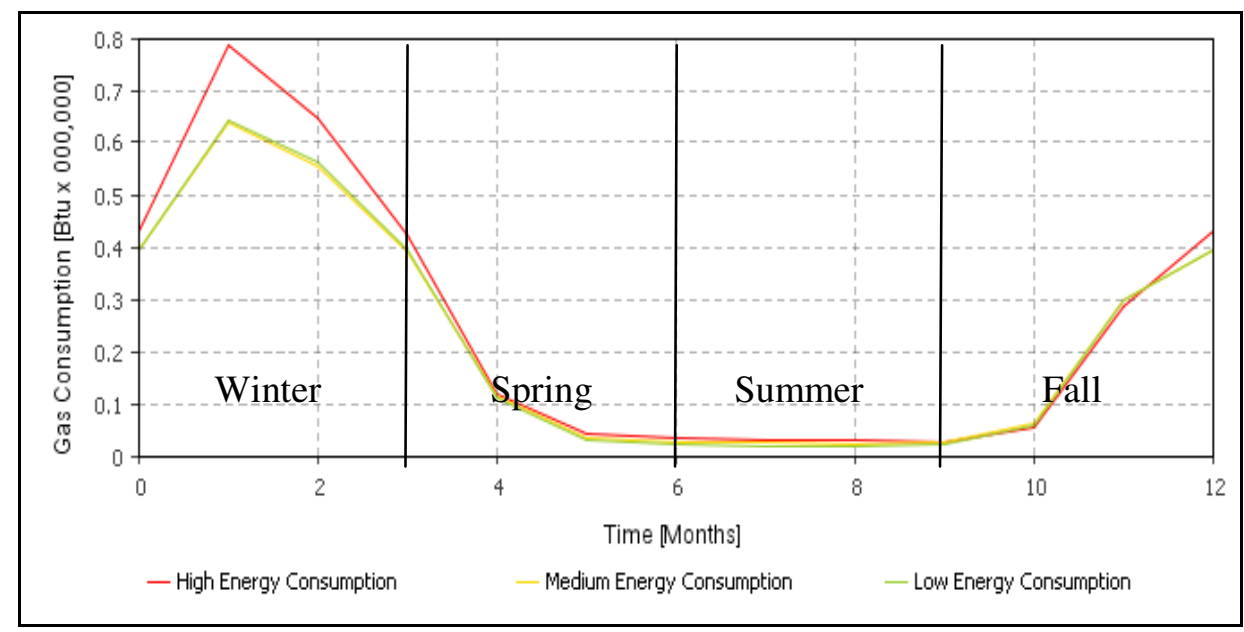

Figure 4: Gas Consumption Comparison

On average, the electric consumption was the highest in the summer season because of the required air conditioning cooling loads. During the same period, the gas consumption was at its lowest since no air conditioning heating loads were required. When comparing the consumption of the three categories of occupants, there is a significant difference in the energy consumption levels when different occupants characteristics are considered. On average, the difference between a high and a low consumer was 39\% for electric consumption, and $11 \%$ for gas.

This bigger difference in electric consumption when compared to gas is due to the higher level of control that occupants have over electric sources than they do over gas sources as shown in Figure 2. As a result, lower differences for gas consumption were observed as expected.

\subsection{Agent-Based Occupant Simulation Model}

In the previous section, energy consumption rates were determined for one person from each category of occupants. This section describes the agent-based model used to simulate the change in the occupants' energy usage characteristics due to the 'word of mouth' effect. This effect represents the influence that occupants have on each other resulting in changes in their energy consumption habits.

The proposed model consists of a user interface where the user enters six different inputs to represent the 10 occupants of the graduate student office previously shown in Figure 1. So first, the initial number of persons in each occupancy category is entered: 'High Energy Consumers', 'Medium Energy Consumers', and 'Low Energy Consumers'. Then the user enters the 'word of mouth' adoption rates, or in other words the probability that a person successfully influences another person in the room to change his/her energy characteristics. Because of the lack of literature on actual rates of influence, the authors assumed the three rates for the 'word of mouth' effects of the three categories of occupants. A sensitivity analysis on these rates will be performed in a future study to better understand the importance of their impact on the simulation results.

In this paper, the authors assumed that 'Low Energy Consumers' have the most effective 'word of mouth' influence through promoting green principles. The 'High Energy Consumers' have an effective however lower 'word of mouth' rate and finally the 'Medium Energy Consumers have the lowest influence on the others due to the assumed neutral attitude that these occupants typically have. These assumptions resulted in the following rates: 0.05 for the 'Low', 0.025 for the 'High', and 0.0125 for the 'Medium Energy Consumers' per month. Stated differently, the rate of 0.05 per month translates into a $5 \%$ chance per month that a low energy consumer successfully influences a high/medium person to change his/her behavior and become a low energy consumer. Because of the probabilistic aspect of these rates (i.e., a chance of 5\%), the more people a certain category has, the more chances this category has to grow over time. For example, in a room where 8 of the 10 occupants are low energy consumers, this majority has 
good chances of successfully influencing the remaining 2 persons over time, who would probably reduce their consumption over time and become low energy consumers.

Figures 5, 6 and 7 show simplified examples of the flow of people that are being converted from a category to another. Figure 5 shows the case where a person from the 'High Energy Consumers' category is influencing other occupants from different categories. In that case, two different flows of people happen. First a person that is in the 'Medium Energy Consumers' category gets converted to the 'High Energy Consumers' category, and second, a person in the 'Low Energy Consumers' category gets converted to the 'Medium Energy Consumers' category. The flow from the low to the medium consumer category shows that the change in characteristics occurs gradually. As a matter of fact, when a 'Low Energy Consumer' gets in contact with a 'High Energy Consumer', he/she gets converted to the 'Medium Energy Consumer' category first, and might get converted to the 'High Energy Consumer' but at a later time. The used rate of conversion for the two flows is 0.025 person/month, which means that each high energy consumer has a $2.5 \%$ chance to successfully convert another person each month. Figure 6 represents the second case where a person from the 'Low Energy Consumers' category is actively converting people and the flow of people is then the opposite of the first case. The rate is however different where a value of 0.05 person/month was used. Finally, when the 'Medium Energy Consumers' category is active, people from the 'High Energy Consumers' and the 'Low Energy Consumers' are directly converted to the 'Medium Energy Consumers' category at a rate of 0.0125 as shown in Figure 7.

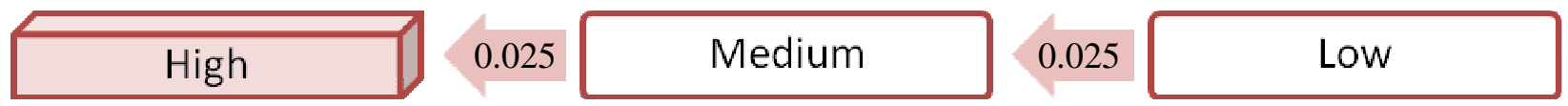

Figure 5: The 'High Energy Consumers' Conversion

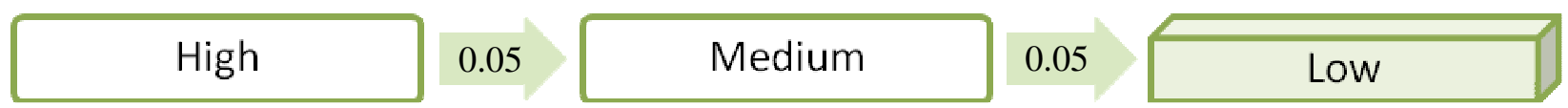

Figure 6: The 'Low Energy Consumers' Conversion

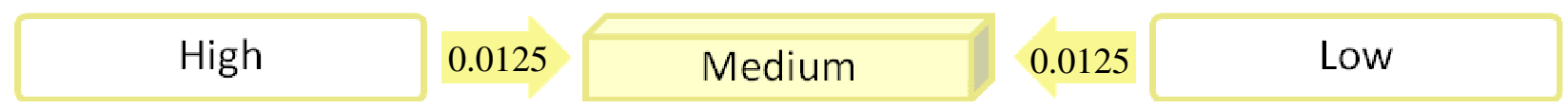

Figure 7: The 'Medium Energy Consumers' Conversion

An example of the change in energy consumption characteristics over time is shown in Figure 8 where the 10 students in the room are interacting according to the rules previously shown in Figures 5, 6, and 7. At the start of the simulation, 3 of the students were assumed to be 'High Energy consumers', 4 'Medium Energy Consumers', and 3 'Low Energy Consumers'. As the simulation time was advancing, low energy consumers represented by the green line were successfully converting all of the medium and high energy consumers to the low consumer category. More specifically, all of the 10 occupants of the room became were low energy consumers after the $48^{\text {th }}$ month. This behavior was expected due to the high 'word of mouth' conversion rate that was used for the low energy consumers that is 0.05 , as opposed to 0.025 and 0.0125 for the high and medium consumers respectively. So in this simulation, the flow of people represented in Figure 6, showing the low consumers 'word of mouth' conversion, was more effective than the other flows shown in Figures 5 and 7. Consequently, low energy consumers were attracting other occupants at a faster rate than they were being attracted, hence their number kept increasing until all of the occupants became low energy consumers. 


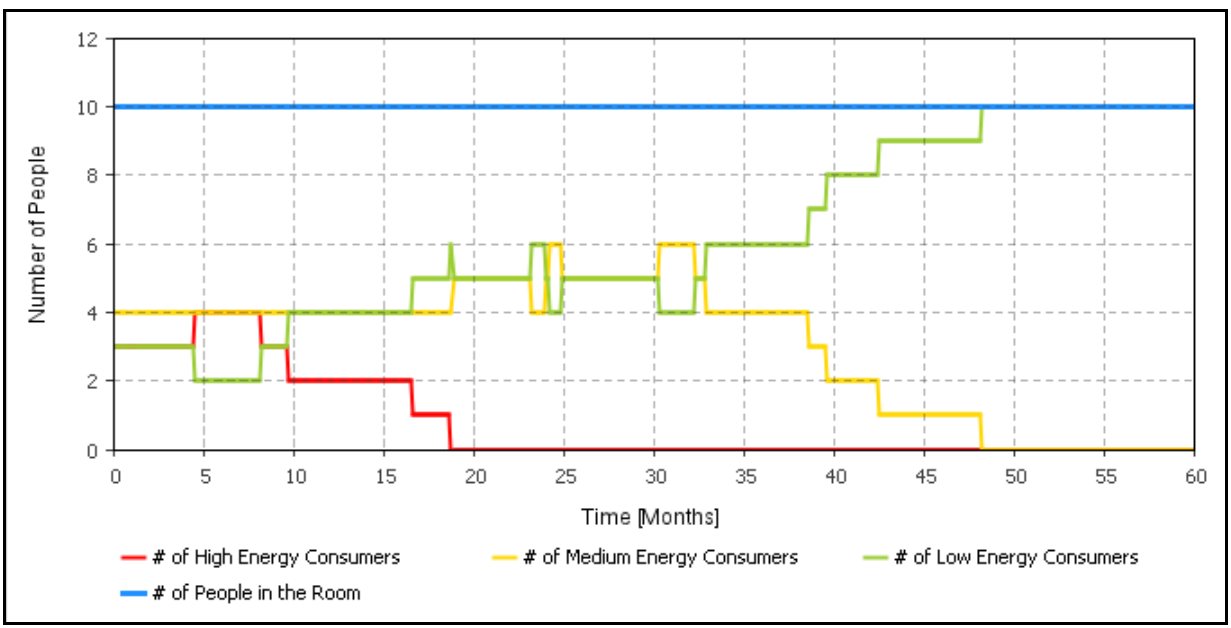

Figure 8: Occupants' Energy Characteristics Change

\subsection{Combining the 'eQuest' and the Agent-Based Simulation Models}

In the previous two sections, the per person energy consumption rates for high, medium, and low energy consumers were determined, then the agent-based model simulated the change in energy consumption characteristics of the 10 occupants of the modeled room over time. The exact numbers of high, medium, and low energy consumers in the room were continuously determined over the 60 months of the simulation period as shown in Figure 8.

In order to get an estimate of the energy consumption of the room over time, the number of people in each category obtained from the agent-based model was continuously multiplied by the corresponding energy consumption rates obtained from eQuest. This way, while energy characteristics of the occupants were changing with time, energy consumption levels were continuously getting updated to account for the changes in energy characteristics. For example, for each of the 60 months shown in Figure 8, the numbers of high, medium, and low energy consumers were continuously multiplied by the corresponding energy consumption rates resulting in total energy consumption levels as shown in Figures 9 and 10. The observed decreases in the total energy levels in Figures 9 and 10 over time are due to the change in occupants' energy usage characteristics. As a matter of fact, Figure 8 shows that as the simulation time advanced, the number of low energy consumers that are represented in the green line increased until all of the 10 occupants of the room became low energy consumers. Since this category of consumers have the lowest energy consumption rates, the total energy consumption levels varied accordingly and dropped over time.

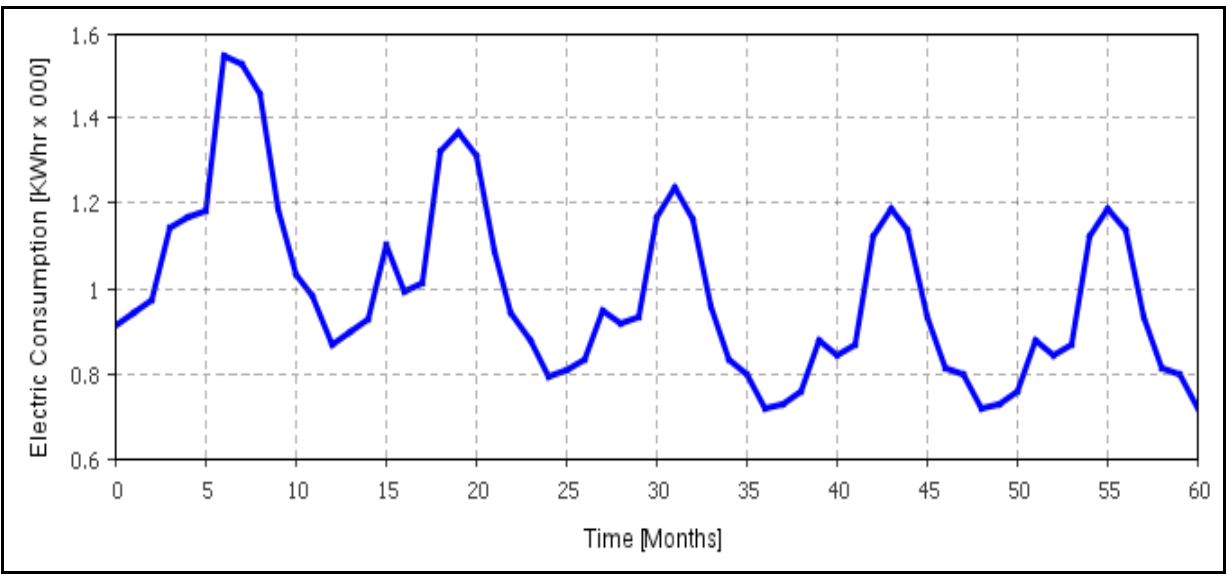

Figure 9: Total Electricity Consumption 


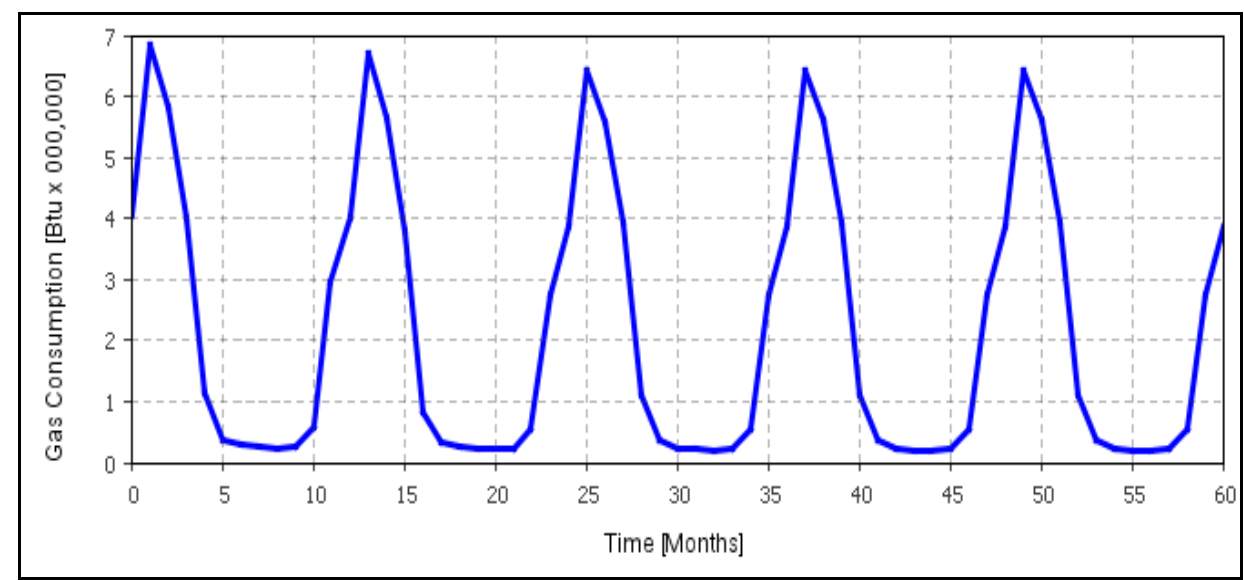

Figure 10: Total Gas Consumption

\section{EXPERIMENTAL MODEL RESULTS AND ANALYSIS}

In this section, the energy consumption estimates for the $1000 \mathrm{sq} \mathrm{ft}$ room with 10 graduate students are calculated for different occupancy scenarios using the proposed methodology. The results from these runs are then compared to a base case estimate obtained from the conventional technique that only uses eQuest, considering all of the room occupants to be 'Medium Energy Consumers', and ignoring any change in energy characteristics over time.

First, three sets of simulations were performed to test the proposed methodology, each with different initial (i.e., time zero) room occupancy characteristics. So at the beginning of each simulation, the 10 occupants of the room were split between high, medium, and low energy consumers in different numbers. So in the first scenario, the initial number of high energy consumers was assumed to be the highest. In the second scenario, it is the medium energy consumers category that had a slight advantage over the others. Finally, the last scenario had the most initial number of persons belonging to the low energy consumers category. The initial assumptions for each of the scenarios are summarized in Table 3.

Table 3: Scenario Study Inputs

\begin{tabular}{|l|l|l|l|l|}
\hline \multirow{2}{*}{} & \multicolumn{4}{|c|}{ Occupancy characteristics at time zero } \\
\cline { 2 - 5 } & Base Case & Scenario 1 & Scenario 2 & Scenario 3 \\
\hline Initial Number of High Energy Consumers & 0 & 5 & 3 & 2 \\
\hline Initial Number of Medium Energy Consumers & 10 & 3 & 4 & 3 \\
\hline Initial Number of Low Energy Consumers & 0 & 2 & 3 & 5 \\
\hline Changes in Energy Characteristics Considered & No & Yes & Yes & Yes \\
\hline
\end{tabular}

For each of the scenarios, the agent-based model simulated the change in energy characteristics over time. Then, using the energy consumption rates for each category of occupants from eQuest, total electric and gas usage were obtained over the total study duration of 60 months. The previously shown Figures 9 and 10 are examples of the type of graphs obtained from each run of the model.

Since the used conversion rates in the agent based model have probabilistic aspects, 20 simulations were performed for each scenario and the means were used to compare the results. The authors deemed that 20 simulations appropriately represented the majority of the possible outcomes of the model. In fact, additional simulations showed that after the $20^{\text {th }}$ run of the model, the results were successfully converging to the obtained means. Table 4 summarizes the results of the runs and shows that the proposed method's numbers can differ by as much as 21.6 percent less and 16.8 percent more electric use from the base case estimates. The differences in the gas use levels are smaller, reaching a maximum of $6.6 \%$ higher than the base case, which is expected due to the low level of control that occupants have on the gas consumption sources as previously shown. 
Azar and Menassa

Table 4: Scenario Study Outputs

\begin{tabular}{|c|c|c|c|c|c|c|c|}
\hline & \multirow{2}{*}{$\begin{array}{c}\begin{array}{c}\text { eQuest } \\
\text { Base Case }\end{array} \\
\text { Value } \\
\end{array}$} & \multicolumn{2}{|c|}{$\begin{array}{l}\text { Proposed Method: } \\
\text { Scenario } 1\end{array}$} & \multicolumn{2}{|c|}{$\begin{array}{l}\text { Proposed Method: } \\
\text { Scenario } 2\end{array}$} & \multicolumn{2}{|c|}{$\begin{array}{l}\text { Proposed Method: } \\
\text { Scenario } 3\end{array}$} \\
\hline & & Value & Variation & Value & Variation & Value & Variation \\
\hline $\begin{array}{l}\text { Total Electric } \\
\text { Consumption } \\
\text { [KWhr x 000] }\end{array}$ & 67.10 & 80.62 & $+16.8 \%$ & 60.86 & $-10.3 \%$ & 55.16 & $-21.6 \%$ \\
\hline $\begin{array}{l}\text { Total Gas Con- } \\
\text { sumption [BTU } \\
\text { x } 000,000]\end{array}$ & 127.67 & 136.11 & $+6.6 \%$ & 129.55 & $+1.8 \%$ & 128.08 & $+0.7 \%$ \\
\hline
\end{tabular}

\section{CONCLUSIONS AND FUTURE WORK}

To conclude, the energy estimates obtained using current building energy modeling techniques are significantly different from actual energy consumption levels. This is causing the industry to consider actual energy simulation software as tools that evaluate alternatives rather than reliably predict energy performance (Hoes et al. 2009; Clevenger and Haymaker 2006). By modeling occupants' energy characteristics and their changes over time, energy estimators could reduce the actual inaccuracy in energy simulation models.

This paper presented a new methodology that combines traditional energy simulation software with agent-based modeling. The energy consumption levels that were obtained from this technique differed by more than $20 \%$ in some cases from the conventional method's estimates. This confirms the important role that occupants' energy usage characteristics play in energy estimation and justifies the need to better account for these characteristics in the energy estimation process.

In this study, only the influence of occupants due to the 'word of mouth' effect was considered. However, the eQuest and the agent-based model can easily be modified to account for any other factor affecting energy consumption, which sets the ground for a multitude of potential future studies. Other studies can also be performed on the actual values of the 'word of mouth' rates that were assumed for this study. For instance, a sensitivity analysis could first be performed to quantify the effect of a change in these rates on the total energy estimate, then a data collection study would help estimate the actual values of these rates based on real-life case studies.

To sum up, by optimizing the proposed method and widening its scope, the proposed dynamic energy estimation method could be an important key to more efficient buildings in the global quest for a more sustainable environment.

\section{REFERENCES}

Allsop, D.T., B.R. Bassett, and J.A. Hoskins. 2007. Word of mouth research: principles and applications. Journal of Advertising Research 47(4):398-411

Bray, M. 2006. Review of Computer Energy Consumption and Potential Savings. Available via < http://www.dssw.co.uk/research/computer_energy_consumption.pdf> [accessed June 9, 2010].

California Energy Commission 2007. Integrated Office Lighting Systems: Making it Personal. Technical Report, Public Interest Energy Research Program, Sacramento, California. Available via <https://touchstoneenergy.cooperative.com/public/programs/EnergyEffi ciency/documents/IntergratedofficeLightingSystemsMakingitPersonal.pdf> [accessed June 9, 2010].

Clevenger C. M. and J. Haymaker. 2006. The Impact of the Building Occupant on Energy Modeling Simulations. 
<http://www.stanford.edu/ haymaker/Research/Papers/Occupant Impact2006-Montreal-Clevenger-Haymaker.pdf> [accessed June 1, 2010]

Dell'lsola, A. J. and S. J. Kirk. 2003. Life Cycle Costing of Facilities. Kingston, MA: Reed Construction Data.

eQuest 2009. Introductory Tutorial, version 3.63.Available via <http://doe2.com/download/equest/eQ-v3-63_Introductory-Tutorial.pdf> [accessed June 1, 2010].

Erickson, V. L., Y. Lin, A. Kamthe, R. Brahme, A. Surana, A.E. Cerpa, M.D. Sohn, and S. Narayanan. 2009. Energy Efficient Building Environment Control Strategies Using Real-time Occupancy Measurements. Available via <http://andes.ucmerced.edu/papers/Erickson09a.pdf> [assessed June 1, 2010].

Harrison-Walker, L.J. 2001. The measurement of word-of-mouth communication and an investigation of service quality and customer commitment as potential antecedents. Journal of Service Research 4(1):60-75.

Hoes, P., J. L. M. Hensen, M. G. L. C. Loomans, B. de Vries, and D. Bourgeois. 2009. User Behavior in Whole Building Simulation. Energy and Buildings, Elsevier 41:295-302.

InterAcademy Council 2007. Lighting the Way: Towards a Sustainable Energy Future. Technical Report, InterAcademy Council, Amsterdam, The Netherlands.

Jackson, T. 2005. Motivating Sustainable Consumption: a review of evidence on consumer behaviour and behavioural change. Technical Report, Centre for Environmental Strategy, University of Surrey, Surrey, United Kingdom.

Railsback, S. F., S.L. Lytinen, and S.K. Jackson. 2006. Agent-based Simulation Platforms: Review and Development Recommendations. Available via <http: / / www . humboldt.edu/ ecomodel/documents / ABMPlatformReview.pdf> [assessed June 1, 2010].

Soebarto, V. I. and T.J. Williamson. 2001. Multi-criteria Assessment of Building Performance: Theory and Implementation. Building and Environment, Elsevier 36(6):681-690.

Turner, C. and M. Frankel. 2008. Energy Performance of LEED for New Construction Buildings. Technical Report, New Buildings Institute, Vancouver, WA. Available via <http://www.usgbc.org/ShowFile.aspx?DocumentID=3930> [accessed June 1, 2010].

United Nations Environment Programme 2007. Buildings Can Play Key Role In Combating Climate Change. Available via <http://www . unep.org/Documents. Multilingual/Default.asp? DocumentID=5 $02 \&$ ArticleID $=5545 \& l=e n>$ [accessed May 18, 2010].

XJTechnologies 2009. Anylogic Overview. Available via <http://www.xjtek.com/anylogic/overview/> [assessed June 1, 2010].

Yudelson, J. 2010. Greening Existing Buildings. New York: Green Source/McGraw-Hill.

\section{AUTHOR BIOGRAPHIES}

ELIE G. AZAR is a graduate student in the Civil and Environmental Engineering Department at the University of Wisconsin-Madison. He received his Bachelor degree in Mechanical Engineering from Polytechnique Montreal. His email is <eazar@wisc.edu>.

CAROL C. MENASSA is an M.A. Mortenson Company Assistant Professor in the Civil and Environmental Engineering Department at the University of Wisconsin-Madison. She received her Ph.D. in Civil Engineering from the University of Illinois at Urbana-Champaign. Her email is $<$ menassa@wisc.edu>. 